\title{
RELATIONSHIP BETWEEN PERSONALITY DIMENSIONS AND PSYCHOLOGICAL WELL- BEING AMONG UNIVERSITY STUDENTS DURING PANDEMIC LOCKDOWN
}

\author{
Kavita Gupta and B.S. Parimal \\ Assistant Professors, Department of Psychology, The Maharaja Sayajirao University of \\ Baroda, Vadodara (Gujarat) India \\ Email: 16kavitagupta@gmail.com,drbsparimal@gmail.com
}

\begin{abstract}
The present study was conducted through Google forms and a sample of 500 university students (250 males; 250 females) in the age range of 18-24 years participated by filling up Sociodemographic measure, the International Personality Item Pool- Big Five Scale and the Ryff's Psychological Well-being scale. Pearson's product correlations and t-test were performed to determine the relationship between Personality dimensions and Psychological well-being of the research participants. Data was analyzed statistically at the level of $p<0.05$. Students high on Extraversion, Neuroticism and Openness to Experience traits are at increased risk of poor Psychological well-being during the Lockdown period. Prospective longitudinal studies are needed to address the limited research on personality change during the Lockdown period. The results from the study showed that there was a statistically significant relationship between Personality dimensions and Psychological well-being, with Extraversion, Openness to Experience, and Neuroticism traits having a negative correlation with Psychological well-being. However, the results also indicated that Agreeableness and Conscientiousness traits have a statistically significant positive relationship with Psychological well-being. Therefore, results indicated that the Big Five Factors explained an important percentage of the variance of Psychological well-being among university students during the Lockdown period.
\end{abstract}

Key words: Personality Dimensions; Psychological Well-being; University Students; COVID-19.

\section{Introduction}

Personality as a terminology could be defined as a dynamic and organized set of characteristics possessed by an individual that uniquely influence his or her cognitions, emotions, interpersonal and social orientation, motivations and behaviors in various aspects of situations. Personality can be defined as the dynamic organization within the individual of those psychophysical systems that determine his unique adjustment to his environment. (G.W. Allport). Field of personality addresses three issues - human universal, individual differences and individual uniqueness. The Big Five personality dimensions were derived from the analysis of natural-language terms used by people to describe themselves (John \& Srivastava, 1999). These were traditionally labeled as Surgency (Extraversion), Agreeableness, Conscientiousness (Dependability), Emotional Stability (vs. Neuroticism) and Culture, Intellect or Openness. Consistency across a wide variety of studies regarding trait-descriptive terms is found, with empirical evidence for the "Big-Five" representation with various reviews (Goldberg, 1992). The usefulness of the structural model in predicting important outcomes in people's lives has been observed in school performance, internalizing disorders, job performance, leadership, and so on. Although the personality traits are stable, individuals can change their pattern of thought, feelings and behavior, indicating the links between the Big Five and important life outcomes, which one can target for personal development and 
change (John \& Srivastava, 1999). Further, Psychological well-being can be defined as an important index of quality of life at the individual and collective level (Siegrist, 2003). Marks and Shah (2004) argued that Psychological well-being (PWB) is more than just happiness or satisfaction - PWB referring to being able to develop as a person and to being fulfilled and happy, and as contributing to the community. Psychological well-being has been defined as a dynamic state characterized by a reasonable amount of harmony between an individual's abilities, needs and expectations, and environmental demands and opportunities (Levi, 1987). Identifying the traits that are related to Psychological well-being is important in securing a complete understanding of well-being as a construct. Psychological well-being is based on a broader approach which includes identity, meaning, and relatedness (Ryff \& Singer, 1996). Psychological well-being is about actualizing human potential and living well; "It is not so much an outcome or end state as it is a process of fulfilling or realizing one's daimon or true nature" (Deci \& Ryan, 2006, p.2).

Research on the good life has increased in recent years through the positive psychology movement. Every individual strives for well-being in terms of Physical, Emotional, and Psychological aspects. Today, in the Pandemic crisis where a complete Lockdown has occurred across the nation, the perceptions of university students regarding the external world in dealing with day to day problems have been affected. With an increase in the Lockdown extension period, the pressure and challenges confronting the individual are extremely high; therefore it is difficult to maintain this sense of well-being in the present scenario. University students are particularly demanding because conflicts relating to quest for identity, concerns for academic success, career and uncertainty about the future all magnify the problems manifold. At this juncture, several mental health disorders have been observed to appear in the majority of university students that would, later on, affect their adjustment in society after the lockdown period is over. Intellectual capacities increase and emotions intensify. Since Personality is a core factor which determines the reactions and adjustments, Psychological-well-being during such a stressed phase among university students should be studied within its perspective.

The present research study aims to study the relationship between Personality dimensions and Psychological well-being amongst university students during pandemic COVID-19 Lockdown. The specific objectives of the study were to find out the relationship between Personality domains (Neuroticism, Extraversion, Openness to experience, Agreeableness, and Consciousness) that probe into a better understanding of the Personality dimensions and Psychological well-being of young university-age male and female students in the present crisis lockdown period. Every morning, with the sunrise, new hopes and many experiences occur that can make subjective perceptions of the impact of Lockdown experiences by capturing the extent to which they felt at several times during their daily life in this crisis situation.

\section{Material and Methods}

The present explorative and cross-sectional study was conducted and a sample of 500 university students (250 males; 250 females) in the age range of 18-24 years filled up the google forms questionnaire. The data was collected through administration of standardized tools, 'International Personality Item Pool (IPIP) scale' consisting of 50 items involving Big-five domains; and 'Ryff Psychological well-being scale' consisting of 42 items. The obtained data was statistically analyzed at the level of $p<0.05$. The present study attempted to investigate the relationship of the Big Five personality factors on Psychological well-being among university students.

\section{Tools}

The data was collected using a self-administered questionnaire through google forms. Google form was developed covering the following domains: 'Socio-demographic profile', 'International 
Personality Item Pool- Big Five Measurement (IPIP-Big Five) (Goldberg et al., 2006) that assesses five traits: Extraversion (e.g. "Am the life of the party"), Agreeableness (e.g., "Sympathize with others feelings"), Conscientiousness (e.g., "Get chores done right away"), Neuroticism (or 'emotional stability' as the other end of the continuum: e.g., "Have frequent mood swings"), and Openness to experience (e.g., "Have a vivid imagination") with Cronbach alpha coefficients of 0.91 for Extraversion, 0.88 for Agreeableness, 0.88 for Conscientiousness, 0.91 for Neuroticism, 0.90 for Openness to experience; and 'Ryff Psychological well-being scale' developed by Ryff and Keyes, (1995) consisting of 42 items with Internal consistencies for the six scales ranging from 0.86 to 0.93 . Inter-correlations between the six factors ranged from 0.32 to 0.76 , raising concerns regarding the distinctness of the factors, especially in terms of the high inter-correlations between Autonomy, Environmental mastery, Personal growth, Positive Relations with others, Purpose in life, and Self-acceptance. Descriptive statistics techniques were applied to discrete and continuous data. Measures such as Mean and Standard deviation were developed from the continuous data. The relative frequency was calculated for discrete data. Pearson correlation test and $t$-test were performed. A p-value $<0.05$ was considered as statistically significant.

\section{Discussion}

Personality may affect well-being either directly_independently of life events—, indirectly via life events, or interactively with life events by moderating their effect on well-being, such as through cognitive appraisal or coping (Bolger \& Shilling, 1991; Bolger \& Zuckerman, 1995; McCrae \& Costa, 1991; Magnus et al., 1993). While positive or negative events are associated with a fluctuation in well-being, this effect is transient because stable person characteristics ensure that an individual is quickly returned to his or her set point.

Table 01: Socio-Demographic Characteristics in the Form of Frequency and Percentage

\begin{tabular}{|c|c|c|c|c|c|c|c|}
\hline \multirow[t]{2}{*}{$\#$ \#. } & \multirow[t]{2}{*}{ Variables } & \multicolumn{2}{|c|}{ Parameters } & \multicolumn{2}{|c|}{ Males $(\mathrm{N}=250)$} & \multicolumn{2}{|c|}{ Females $(\mathrm{N}=250)$} \\
\hline & & & & $\begin{array}{c}\text { Frequency } \\
(n)\end{array}$ & $\begin{array}{c}\text { Percentage } \\
(\%)\end{array}$ & $\begin{array}{c}\text { Frequency } \\
(n)\end{array}$ & $\begin{array}{c}\text { Percentage } \\
(\%)\end{array}$ \\
\hline 1. & Age & $\begin{array}{l}\text { a. } \\
\text { b. } \\
\text { c. } \\
\text { d. } \\
\text { e. } \\
\text { f. } \\
\text { g. }\end{array}$ & $\begin{array}{l}18 \text { years } \\
19 \text { years } \\
20 \text { years } \\
21 \text { years } \\
22 \text { years } \\
23 \text { years } \\
24 \text { years }\end{array}$ & $\begin{array}{c}52 \\
70 \\
72 \\
28 \\
18 \\
8 \\
2\end{array}$ & $\begin{array}{c}20.8 \\
28.0 \\
28.8 \\
11.2 \\
7.2 \\
3.2 \\
0.8\end{array}$ & $\begin{array}{c}42 \\
74 \\
84 \\
37 \\
9 \\
2 \\
2\end{array}$ & $\begin{array}{c}16.8 \\
29.6 \\
33.6 \\
14.8 \\
3.6 \\
0.8 \\
0.8\end{array}$ \\
\hline 2. & Type of family & $\begin{array}{l}\text { a. } \\
\text { b. } \\
\text { c. }\end{array}$ & $\begin{array}{l}\text { Nuclear } \\
\text { Joint } \\
\text { Extended }\end{array}$ & $\begin{array}{c}147 \\
92 \\
11 \\
\end{array}$ & $\begin{array}{c}58.8 \\
36.8 \\
4.4 \\
\end{array}$ & $\begin{array}{c}176 \\
66 \\
8 \\
\end{array}$ & $\begin{array}{c}70.4 \\
26.4 \\
3.2\end{array}$ \\
\hline 3. & Presently Residing & $\begin{array}{l}\text { a. } \\
\text { b. } \\
\text { c. }\end{array}$ & $\begin{array}{l}\text { Hostel } \\
\text { Local } \\
\text { PG }\end{array}$ & $\begin{array}{c}120 \\
103 \\
27\end{array}$ & $\begin{array}{l}48.0 \\
41.2 \\
10.8\end{array}$ & $\begin{array}{c}107 \\
112 \\
31\end{array}$ & $\begin{array}{l}42.8 \\
44.8 \\
12.4\end{array}$ \\
\hline 4. & Socio-economic status & & $\begin{array}{l}\text { LMSES } \\
\text { MSES } \\
\text { UMSES }\end{array}$ & $\begin{array}{c}31 \\
117 \\
102\end{array}$ & $\begin{array}{l}12.4 \\
46.8 \\
40.8\end{array}$ & $\begin{array}{c}23 \\
118 \\
109\end{array}$ & $\begin{array}{c}9.2 \\
47.2 \\
43.6\end{array}$ \\
\hline
\end{tabular}

Source: Field Survey by author

*Participants in the two groups, i.e., Male and Female University students $(N=500)$

In the present study, 250 male students with a mean of $19.68 \pm 1.35$ and 250 female students with a mean of $19.64 \pm 1.15$ participated in the study. From the table no.1, it can be observed that amongst the male participants, 58.8 percent were from the nuclear family, 36.8 percent were from a joint family, and 4.4 percent from extended family. On the other hand, amongst the female participants, 70.4 percent were from a nuclear family, 26.4 percent were from a joint family, and 3.2 percent from extended family. Moreover, 48 percent, 41.2 percent, and 10.8 
percent male research participants were residing in a hostel, local and PG respectively at the time of data collection. 42.8 percent, 44.8 percent, and 12.4 percent female research participants were residing in a hostel, local and PG respectively at the time of data collection. 12.4 percent of the male research participants belonged to lower economic status, followed by 46.8percent in the middle class and 40.8 percent in the upper socio-economic status. 9.2 percent of the female research participants belonged to lower economic status, followed by 47.2 percent in the middle class and 43.6 percent in the upper socio-economic status.

Table 02: Socio-demographic characteristics in the form of Mean and Standard Deviations

\begin{tabular}{|l|c|c|}
\hline \multicolumn{1}{|c|}{ Variables } & Males (Mean \pm SD) & Females (Mean \pm SD) \\
\hline Age & $19.68 \pm 1.35$ & $19.64 \pm 1.15$ \\
\hline Type of family & $1.45 \pm 0.58$ & $1.32 \pm 0.53$ \\
\hline Presently Residing & $1.62 \pm 0.67$ & $1.69 \pm 0.67$ \\
\hline Socio-economic status & $2.28 \pm 0.67$ & $2.34 \pm 0.64$ \\
\hline
\end{tabular}

Source: Field Survey by author

${ }^{*}$ Participants in the two groups, i.e., Male and Female University students $(N=500)$

Table 03: Tabular representation of the correlations between Personality dimensions and Psychological well-being of University students $(N=500)$

\begin{tabular}{|l|c|}
\hline \multicolumn{1}{|c|}{ Personality dimensions } & $\begin{array}{c}\text { Psychological well-being } \\
(\boldsymbol{r}-\mathbf{v a l u e})\end{array}$ \\
\hline Openness to Experience & $-0.123^{\star *}$ \\
\hline Conscientiousness & $0.187^{\star *}$ \\
\hline Extraversion & $-0.171^{* *}$ \\
\hline Agreeableness & $0.261^{* \star}$ \\
\hline Neuroticism & $-0.164^{* *}$ \\
\hline Overall Personality & $0.311^{\star *}$ \\
\hline
\end{tabular}

** Significant at 0.01 level; * Significant at 0.05 levels.

The group correlations were carried out between the dimensions of Personality and Psychological well-being. The results illustrated above indicate that there is a significant correlation between Personality dimensions and Psychological well-being of the research participants.

From table no. 3, it can be seen that Overall Personality dimensions are significantly correlated with the psychological well-being of the students. Further, Openness to experience trait was observed to be negatively correlated with Psychological well-being $\left(r=-0.123^{\star *}\right)$. Conscientiousness trait was observed to be positively correlated with the Psychological well-being $\left(r=0.187^{* *}\right)$. Extraversion trait was observed to be negatively correlated with the Psychological well-being $\left(r=-0.171^{* *}\right)$. Agreeableness trait was observed to be positively correlated with the Psychological well-being $\left(r=0.261^{* *}\right)$. Neuroticism trait was observed to be negatively correlated with the Psychological well-being $\left(r=-0.164^{\star *}\right)$. All the results were found to be statistically significant at $p<0.05$.

From table no. 4 , it could be depicted that there existed a significant gender difference in the Psychological well-being of the research participants $\left(t=-6.678^{* *}\right)$. 
Table 04: Independent Samples t-Test for Gender \& Psychological Well-Being

\begin{tabular}{|l|c|c|c|}
\hline \multicolumn{1}{|c|}{ Group } & Mean & Standard Deviation & $\boldsymbol{t}$-value \\
\hline Male & 152.74 & 13.27 & $-6.678^{\star \star}$ \\
\hline Female & 163.428 & 21.51 & \\
\hline
\end{tabular}

** Significant at 0.01 level; *Significant at 0.05 levels.

Table 05: Differences in responses of Male and Female Students

\begin{tabular}{|l|c|c|c|c|c|c|}
\hline \multirow{2}{*}{ Variable } & \multicolumn{2}{c|}{ Male } & \multicolumn{2}{c|}{ Female } & \multirow{2}{*}{-value } & P-value \\
\cline { 2 - 6 } & M & SD & M & SD & & \\
\hline Autonomy & 26.01 & 4.38 & 26.63 & 4.92 & -1.496 & $0.05^{*}$ \\
\hline Environmental Mastery & 25.07 & 3.80 & 27.86 & 5.54 & -6.542 & $<0.001^{* *}$ \\
\hline Personal Growth & 25.46 & 3.72 & 27.10 & 4.93 & -4.204 & $<0.001^{* *}$ \\
\hline Positive Relations with others & 24.84 & 3.68 & 25.88 & 4.71 & -2.748 & $0.001^{* *}$ \\
\hline Purpose in Life & 26.39 & 4.14 & 28.39 & 5.87 & -4.396 & $<0.001^{* *}$ \\
\hline Self-acceptance & 24.96 & 3.06 & 27.54 & 5.45 & -6.541 & $<0.001^{* *}$ \\
\hline
\end{tabular}

** Significant at 0.01 level; * Significant at 0.05 levels.

The above table illustrates that there exists a significant difference in the sub-dimensions of Psychological well-being among male and female respondents, viz., Autonomy, Environmental Mastery, Personal Growth, Positive Relations with Others, Purpose in Life and Self-acceptance.

Estimates of correlations between the Big Five factors and Psychological well-being are based on only a few empirical studies. Schmutte and Ryff (1997) examined the relationship between Personality and Psychological well-being, controlling for source and measurement overlap in the affective and evaluative content of items. They found that Psychological well-being was linked to all of the Big Five factors. In particular, large correlations were observed between Conscientiousness and purpose in life, Agreeableness and Positive relations, and Openness to experience and personal growth. The study showed that neuroticism is negatively correlated with psychological well-being. A similar result was observed in a study conducted (Abbott et al., 2008) on a sample size of 1134 women in the age range of 16-26 years with an objective to assess the relationship between personality dimensions and psychological well-being by administering Maudsley personality inventory and Ryff's psychological well-being scale. This study clearly indicated that people with high neuroticism possess a low level of psychological well-being due to irrational ideas, inability to control their impulses and cope up appropriately with stress. In a study conducted (Salami, 2011) on a sample of 400 Adolescents from secondary school in South Western Nigeria with an objective to examine the relationship between the BIG-FIVE Personality factors and psychological well-being of adolescents and the moderating role of emotional intelligence in that relationship by administering NEO-FFI, Emotional Intelligence and psychological well-being scale (Ryff \& Keys, 1995). As a result, it was observed that a significant correlation existed between psychological well-being and personality factors. Past studies by Kjell, Nima, Sikström, Archer and Garcia, (2013); and Motevaliyan, (2014) and Bradburn (1969); Librán (2006) showed a significant relationship between neuroticism and adolescent psychological well-being. Similarly, Joshanloo and Afshari, (2011) found a negative significant relationship between neuroticism and psychological well-being. Moreover, respondents with low neuroticism personality traits may present more social adjustment, modesty, dutifulness and well-being. Therefore, the adolescent with high neuroticism personality traits is usually anxious, depression, moody, vulnerability and emotionally not stable (Garusifarshi, 2007). Clearly, adolescents with high neuroticism personality might not be able to do his/her duty well. The finding from this study also indicated positive significant relationships between extraversion and agreeableness traits and adolescent psychological well-being. This finding is consisted of (Garusifarshi, 2007; HaghShenas, 2010; Joshanloo and Rastegar, 2007) argued that there were positive relationships between extraversion and adolescent's psychological wellbeing. Findings from Costa and McCrae 
(1980) argued that satisfaction with life is related to a high level of extraversion and a low level of neuroticism.

These research findings are to be discussed in the context of the "Big five factors" Model. The five factors if Personality is very stable and has been validated in cultures around the world. Personality is dynamic but as human beings grow up, the deeply rooted traits and beliefs need consistent efforts to change it. The past researches support that the crisis brings with it another crisis; mental health is an integral part of Psychological well-being. There is no doubt that there is a lot of uncertainty around the current coronavirus outbreak. This study conducted in this crisis shows a negative correlation between three dimensions and Psychological well-being. In this lockdown period, a social animal has to be forced to be a social distancing animal. Extraverted people are sociable, outgoing and actively engaged with the world. It becomes difficult to get adapted to isolation and getting conditioned to detach from others. This study supports these types of Personality lead towards adverse effect to Psychological well-being. Findings on Extraversion, some studies reported positive and negative correlations with academic success (Trapmann, 2007; Goldberg 2001). This study also investigated the negative impact of this trait on Psychological well -being of students. Adolescents and youth in the field of higher education have peer group influence, and Sociability and the physical company gives them boost to their selfesteem but in this study, it is crystal clear that forced Social Distancing and isolation adversely affected their Psychological well- being.

People high in neuroticism are tense, anxious, moody and more emotionally reactive to events than emotionally stable people. In this crisis, many people have been observed having a feeling of hopelessness and meaninglessness. During the corona, crisis loneliness is very normal and the discomfort it brings leads to a lack of neurotransmitters in the brain called Oxytocin this is also known as love hormone or a feel-good factor that is produced in response to physical touch and eye contact. Coronavirus has restricted the people to touch. So, the result shows higher Neuroticism lowers the well-being. Prior research has established that both Neuroticism and learning styles are associated with academic achievement. Neuroticism refers to the degree of emotional instability and insecurity. This has been reflected in this study of students' behavior as a result of fear of death, sense of meaningfulness, homesickness in hostel staying for a prolonged period due to the corona crisis. Students' high score on neuroticism indicates disengagement of students from the learning process and inconsistency in facing difficulties hence it was found how this dimension is related to the Psychological well-being of students.

The contradiction in the correlation between Openness to Experience and Psychological well-being found people of these personalities usually are very creative and have a preference for a variety of novelty and aesthetics. During the lockdown period people have enough time to be innovative and develop some skills. From the findings of this study perspective it is assumed due to some limitations, restrictions or lack of sources needs are not satisfied which leads to negative effects on open-minded personally. Openness to experience has been found positively related to academic performance in several studies. (Barthelemy and Lounsbury, 2009). This was attributed to the association of openness to experience with intellectual ability and curiosity (Premuzic and Furnham, 2003). The major focus of this study was students' well-being from personality traits perspective. Openness to experience is a positive trait in the five-factor model which says a person willing to try new things and be creative. In this study students' responses are negatively related to their well-being. Low scores on this dimension show a lack of ability in students to get adapted to a big change like Quarantine. In field of Education, it is a transition period from traditional learning to online learning. They are not open to new innovation is a reflection of anxiety which led them stagnation surrounded by uncertainties for their future career and pressure of examination. 
Conscientiousness personality is very self-disciplined and well organized and selfcontrolled. These people don't face difficulties to observe law and order situations. Whereas on other end, against this in this crisis many cases have been recorded on dimension directedness where people lose their temper, restore to violence. These unprecedented COVID- 19 situations led to many problems like economy disaster, unemployment, poverty, health issues, mental health problem, interpersonal relationship problems. People on the Agreeableness dimension show in this study high Psychological well-being. These people have concern for other people, cooperative and helping nature. They donate money, they standby people in crisis.

\section{Limitations}

1. Firstly, this research employed a google form survey method.

2. Secondly, data was collected from students studying in universities in Vadodara at a single point in time. Therefore, the generalizability of the findings is limited.

3. Lastly, to collect data only self-report measures were used and future research should attempt to include other sources of data.

4. On the other hand, the study was also limited to the assumption that the students truthfully participated in the study by marking the best options in the surveys to reflect themselves and providing the researchers with genuine information about their Personality and Psychological well-being.

\section{Recommendations}

1. It is recommended that Longitudinal or Experimental studies may be conducted to determine how personality traits might affect one's vitality and to establish the direction of causality of Psychological well-being in this lockdown period.

2. Furthermore, cross-cultural studies can be conducted in order to determine the impact of personality traits on Psychological well-being among the students under pandemic lockdown situation.

3. The future studies may investigate variables such as Self-esteem, Cognitive flexibility and Psychological vulnerability that may mediate the relation between Personality traits and Psychological well-being.

4. Future studies may use multiple assessment methods such as telephonic interviews to strengthen the validity of the findings in this lockdown phase.

5. Considering the above negative impacts of the crisis on students' Psychological well-being for enhancement of mental health and adjustment ability, Rational Emotive Behavior Therapy, Existential Counselling and other coping strategies to develop resilience in students to be suggested.

\section{Implications}

The findings of the present study shed lights on the relationship between Personality dimensions and Psychological well-being of the university students during a pandemic COVID-19 Lockdown. The results obtained from this study would lay a foundation for future studies on the same lines.

1. It will be helpful to solve the problem of university students in the present scenario.

2. To evaluate the effect of counseling.

3. Treatment planning.

4. Guidance.

This awareness could help the university instructors with new roles in educating and supporting students struggling with Psychological well-being. These new roles may necessitate 
them to help their students regulate their daily schedule and learn how to adjust in the present situation more efficiently. The major tasks during this phase include establishing self-exploration, self-expression, realizing one's identity and capabilities and preparing for self-reliance.

\section{Conclusion}

After going through all the steps of the investigation, an effort had been made to present various findings incoherent manner as follows:

1. There is a positive co-relation between Personality dimensions and Psychological well-being of university students.

2. There is a negative relationship between Openness to Experience and the Psychological wellbeing of university students.

3. There is a positive relationship between Conscientiousness and Psychological well-being of university students.

4. There is a negative relationship between Extraversion and Psychological well-being of university students.

5. There is a positive relationship between Agreeableness and Psychological well-being of university students.

6. There is a negative relationship between Neuroticism and the Psychological well-being of university students.

7. There exist a gender difference with respect to Psychological well-being among research participants.

The findings of the study revealed that there exists a significant positive relationship between Personality dimensions and Psychological well-being of university students. The study revealed that a significant positive relationship exists between Agreeableness, Conscientiousness, and Psychological well-being followed by a significant negative relationship between Extraversion, Openness to experience and Neuroticism and Psychological well-being of the research participants. All the results were found to be significant at $p<0.05$.

Despite considerable research on Personality and Psychological well-being, the current study investigated the relationship between the Big Five traits and Psychological well-being among 500 university students. Results indicated that the relationship between Personality factors and Psychological well-being was stronger suggesting that these traits represent the personality predispositions for general well-being. However, the Personality correlates of the dimensions within each broad well-being type varied, suggesting that the relationship between personality and Psychological well-being is best modeled in terms of associations between specific traits and wellbeing dimensions.

In conclusion, the results from this study showed that personality traits play a vital role to determine the level of Psychological well-being among university students in Vadodara, Gujarat. Thus, it is necessary that students should be equipped with appropriate abilities, skills and knowledge through parental or peer group support or through tele-counseling so that they can have better adjustment with the present situation of the Pandemic COVID-19 Lockdown scenario.

\section{References}

1. Abbott, R. A., Croudace, T. J., Ploubidis, G. B., Kuh, D., Richards, M., \& Huppert, F. A. (2008). The relationship between early personality and midlife psychological well-being: evidence from a UK birth cohort study. Social psychiatry and psychiatric epidemiology, 43(9), 679. 
2. Barthelemy, J.J., Lounsbury, J.W. (2009). The Relationship Between Aggression and the Big Five Personality Factors in Predicting Academic Success. Journal of Human Behavior in the Social Environment, 19:2, 159-170, DOI: 10.1080/10911350802687125

3. Baumgardner, S. R. \& Crohters, M. K. (2009). Positive Psychology, published by D. Kindersley (India) Pvt. Ltd. Licensees of Pearson Education in South Asia.

4. Chamorro-Premuzic, T, Furnham, A. (2003). Personality predicts academic performance: Evidence from two longitudinal university samples. Journal of Research in Personality, 37: 319-338.

5. Christopher, J.C. (1990). Stating psychological well-being; exploring the structural roots of its theory and research. Journal of counseling and development, 77, 144-152.

6. Ciccarelli, S.K., \& White, J.N. (2015) Psychology. (4 ${ }^{\text {th }}$ ed.), 1-785. Upper Saddle River, NJ: Pearson Education.

7. Dinner, E. (1994). Subjective well-being, psychological bulletin 95, 542-575.

8. Engin, Deniz M., \& Ahmet Satici, Seydi (2017). The Relationships between Big Five Personality Traits and Subjective Vitality. Anales de Psicología, 33(2),218-224. [fecha de Consulta 27 de Abril de 2020]. ISSN: 0212-9728. Disponible en: https://www.redalyc.org/articulo.oa?id=167/16750533002

9. Fayombo, G. (2010). The relationship between personality traits and psychological resilience among the Caribbean adolescents. International Journal of Psychological Studies, 2(2), 105116.

10. Goldberg, L. R., Johnson, J. A., Eber, H. W., Hogan, R., Ashton, M. C., Cloninger, C. R., \& Gough, H. G. (2006). The international personality item pool and the future of public-domain personality measures. Journal of Research in Personality, 40(1), 84-96. https://doi.org/10.1016/j.jrp.2005.08.007

11. Goldberg, L.R. (2001). Frozen by success: Why we don't know nearly enough about the relations between personality attributes and academic performance. Remarks delivered at the E.T.S. Workshop: Applications to new constructs, Educational Testing Service, Princeton, NJ.

12. Goldberg, L. R. (1992). The development of markers for the Big-Five factor structure. Psychological Assessment, 4(1), 26-42. https://doi.org/10.1037/1040-3590.4.1.26

13. Hall, C.S., Lindzey, G., \& Campbell, J.B. (1988). Theories of Personality. (4 ${ }^{\text {th }}$ ed.), $1-722$. New York, NY: J. Wiley \& Sons.

14. John, O. P., Naumann, L., \& Soto, C. J. (2008). Paradigm shift to the integrative Big Five taxonomy: History, measurement, and conceptual issues. In O. P. John, R. W. Robins, \& L. A. Pervin (Eds.), Handbook of personality: Theory and research (3rd ed., pp. 114-158). New York, NY: Guilford.

15. Mohanty, G. (2012). Textbook of Psychology. (3 ${ }^{\text {rd }}$ ed.), 1-450. New Delhi, DL: Kalyani Publishers.

16. Mobarakeh, M.R.V., Juhari, R., Yacoob, S.N., Redzuan, M., Mobarakeh, S.I. (2015). The Effects of Personality Traits and Psychological Well-Being among Iranian Adolescent Migrants in Kuala-Lumpur, Malaysia. IOSR Journal of Humanities And Social Science, Volume 20, Issue 7, Ver. I, 25-28. e-ISSN: 2279-0837, p-ISSN: 2279-0845.

17. Ryan, R. M., \& Deci, E. L. (2001). On happiness and human potentials: A review of research on hedonic and eudaimonic well-being. Annual review of psychology, 52(1), 141-166.

18. Ryff, C (1989). Happiness is everything, or is it not? Exploration of the meaning of psychological well-being. Journal of personality \& social psychology, 57,1064-1081.

19. Ryff, C. \& Keyes, C. (1995). The structure of psychological well-being revised. Journal of Personality \& social Psychology 69, 719-727.

20. Perez, J.A(2012). Gender differences in psychological wellbeing among Filipino college students' sample. International journal of humanities \& social sciences, 2.

21. Pervin, L.A., Cervone, D., \& John, O.P. (2005). Personality theory research, $9^{\text {th }}$ ed. 
22. Sagone, E., \& De Caroli, M. E. (2014). Relationships between psychological well-being and resilience in middle and late adolescents. Procedia-Social and Behavioral Sciences, 141, 881 887.

23. Salami, S.O. (2011). Social behavior and personality. An international journal, 39, 785-794.

24. Seligman, M. E., \& Csikszentmihalyi, M. (2014). Positive psychology: An introduction. In Flow and the foundations of positive psychology (pp. 279-298). Springer, Dordrecht.

25. Singh, A.K. (2006). Uchchatar Samanya manovigyan, $5^{\text {th }}$ ed.

26. Synder, C. R. \& Lopez, S.J. positive psychology. The scientific \& practical exploration of human strengths. University of Kansas, Lawrence. Sage publication.

27. Trapman, S., Hell, B., Hirn, J. W., \& Schuler, H. (2007). "Meta-Analysis of the Relationship between the Big Five and Academic Success at University". Journal of Psychology, 215, 132 151. 